Indexed by

\title{
Scopus
}

\section{THE IMPACT OF ACTUATED CONTROL ON THE ENVIRONMENT AND THE TRAFFIC FLOW}

Crossref

\section{KOBSON}

\section{Ján Beňuš}

Department of Road and Urban Transport University of Žilina, Žilina 01026,

Slovakia

\section{Ambróz Hájnik}

Department of Road and Urban Transport University of Žilina, Žilina 01026, Slovakia

\author{
Veronika Harantová \\ Department of Road and \\ Urban Transport University \\ of Žilina, Žilina 01026 , \\ Slovakia
}

\author{
Stanislav Kubal'ák \\ Department of Road and \\ Urban Transport University \\ of Žilina, Žilina 01026, \\ Slovakia
}

Key words: intersection, delay time, emissions, simulation, fixed control, actuated control doi:10.5937/jaes0-33043

\section{Cite article:}

Kalašová A., Hájnik A., Kubal'ák S., Beňuš J., Harantová V. (2022) THE IMPACT OF ACTUATED CONTROL ON THE ENVIRONMENT AND THE TRAFFIC FLOW, Journal of Applied Engineering Science, 20(2), 305 - 314, DOI:10.5937/ jaes0-33043 


\title{
THE IMPACT OF ACTUATED CONTROL ON THE ENVIRONMENT AND THE TRAFFIC FLOW
}

\author{
Alica Kalašová, Ambróz Hájnik*, Stanislav Kubal'ák, Ján Beňuš, Veronika Harantová \\ Department of Road and Urban Transport University of Žilina, Žilina 01026, Slovakia
}

In our paper, we have analyzed and compared fixed and actuated control at a chosen intersection, where we pointed out the importance of actuated control and its benefits. We have used traffic data from sensors in the roadway. The intersection was modelled in Aimsun, where we performed simulations. The research focused mainly on the impact of actuated control on the basic characteristics of the traffic flow, delay time and emissions. The outputs of simulations showed positive results of actuated control in all compared values. The environmental pollution topic is up-to-date and road transport has a significant impact on it. Furthermore, we want to continue with our research to investigate the impact of speed changes on emission production and the smoothness of the traffic flow under fixed and actuated control.

Key words: intersection, delay time, emissions, simulation, fixed control, actuated control

\section{INTRODUCTION}

Road transport is still the most attractive mode of transportion for majority of the population. The increasing flow of vehicles causes many issues, including congestion of traffic, noise pollution, accidents, longer travel times, etc [1-5]. Road network expansion is slow and often not possible [6]. Therefore, it is necessary to look for other solutions to ensure smooth and sustainable transport. A major problem of the road network is intersections points where several traffic flows meet $[7,8]$. It is vital to enable actuated control (intelligent traffic management) at signal-controlled intersections, which will allow the maximum number to pass through and reduce the delay time. There are several ways to solve the well-known traffic issues within cities. Increasing preference for public transport is the first solution to current traffic issues. This preference means prioritizing public transport over individual automobile transport (IAT). For example, it is the preference at signal-controlled intersections or in the form of traffic signs (bus lane). However, this does not solve the problem with the growth of vehicle convoys, $[9,10]$. On the other hand, if more people were willing to switch to public transport from IAT, traffic becomes smoother (the volume of emissions produced will decrease as a direct result of the reduction of vehicles on the road) [11-13]. The preference is necessary to ensure the attractiveness of public transport [14]. Also, electrification is an important way to increase the attractivity of public transport and reduce its negative impact on the environment $[15,16]$. In addition to public transport, it is necessary to build and maintain infrastructure for pedestrians and cyclists since they help reduce the number of vehicles [17]. The second way to solve the problem is widening roads (both increasing the number of lanes as well as building new roads), building multi-level intersections and city bypasses that divert transit traffic outside the central part of cities or outside cities in general
$[18,19]$. Though this is an effective solution because it is a very expensive one it is often viewed as unfeasible $[6,20]$. The third way is dynamic optimization of traffic management (actuated control). For example, enforcing a control system using light signalling devices at intersections. Traffic management is the crucial way for the efficient managing of transport at intersections and roads in cities [22]. Actuated control is an effective way to manage intersections in many parts of the world [23-26].

"The key to ensuring the effectiveness of actuated control lies in the capability of timely updating the signal timing parameters responding to actual arrivals at entrances of the intersection. Conventionally, this can be achieved by adjusting actuated control parameters" [21]. These parameters include adjusting maximum pedestrian waiting times, cycle length, gap times, detector locations and minimum/maximum green time $[27,28]$. On one hand, there are various principles when optimizing traffic signal timing by combining data from connected vehicles on the loop detector data [29], using trajectory data of the connected vehicle [30], the floating car data [31]. Howev$\mathrm{er}$, there are not enough connected vehicles in real-time traffic to collect adequate traffic data. Currently, it is possible to gather real-time data on urban traffic via sensors, detectors or mobile apps $[32,33,6]$. This data along with calculation methods can assist in significantly improving the dynamic of traffic management [34-41]. Various intelligent traffic solutions are advancing in the world. These include intelligent transport systems and traffic management data, which use the Internet of Things to improve transport and thus provide higher living standards to its people [42]. The study in Thessaloniki describes the integration of an intelligent transport system (ITS) "in urban mobility management with an achieved goal of balanced ("sustainably smart") use of transport networks, in compliance with the principles of sustainable urban mobility" [43]. Artificial intelligence is a way to manage traffic efficiently to ensure smooth traffic flow. At present, 
there are several intelligent traffic management solutions and systems that are achieving positive results. One of these solutions is dynamic traffic management. Another solution is actuated control at intersections, ex. implementing dynamic speed limits (DSL). These speed limits are mainly used on motorways [47] and ensure smooth traffic flow reducing traffic accidents, environmental conditions, etc. [44-46]. The study [48] describes ITS solution of dynamic traffic management - the green navigation system. It helps drivers save fuel as well as have a positive impact on the environment (reduce pollution). A necessary prerequisite for the creation, implementation, assessment and subsequent optimization of ITS is traffic data. Traffic data includes collection information on the flow, speed, density, vehicle category, weather conditions, traffic accidents, etc. Smart and sustainable mobility systems are part of a smart city concept. They help to reduce the negative impact of transport $[49,50]$. Therefore, it is also important to support these low-emission systems in cities. [51]

\section{MATERIALS AND METHODS}

Actuated control systems began to develop in the mid1980s. At present, it is possible to find a signal-controlled intersection with actuated control in almost every town in Slovakia. As part of the research, we chose a signal-controlled intersection in the town of Ružomberok (see Fig. 1). Data at hourly intervals (24 hours) was provided to us by the company managing this intersection.

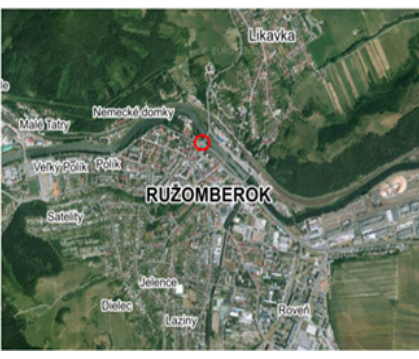

a)

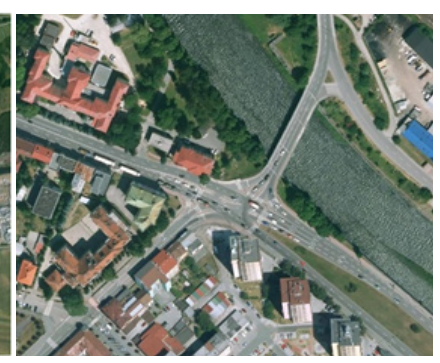

b)
Figure 1: Intersection - (a) Location in Ružomberok and (b) Detail of intersection [52]

The intersection is part of the main route that connects eastern and western Slovakia. A total of 40,551 vehicles were recorded at the intersection over the span of 24 hours. The highest flow of vehicles entered the intersection between 15:10 and 16:10 - 2,763 vehicles. The lowest flow of vehicles - 180 vehicles - entered the intersection from $02: 10$ to $03: 10$. In the following figure 2, you can see the routing of individual traffic flows and the number of vehicles for each of them. These numbers are in units "veh/h" (vehicles per hour). For our research, we used Aimsun, a traffic modelling software developed by TSS Transport Simulation Systems. It is used to improve the smoothness of traffic flow along with reducing emissions and congestion, etc. Aimsun is based on the Gipps safe distance model, which consists of 2 conflicting acceleration and deceleration requirements. Acceleration is a requirement of a vehicle to reach a given speed in a given section of road. However, this requirement is affected by the restrictions imposed by the previous vehicle. $[53,54]$. Aimsun simulated the emission values based on a study by Panis et al. (2006) [55]. Aimsun allows traffic planners the:

1. Ability to accurately represent the geometry of the road network.

2. Detailed modelling of individual vehicles behaviour.

3. Definite reproduction of traffic management plans.

4. Output of the simulation runs - 2D and 3D animations, graphs, tables [56].

The basis for traffic planning and modelling is the analysis of traffic flow data. Traffic modelling, whether microscopic or macroscopic, is an effective method of assessing and examining the current state in order to provide possible reccomendations or solutions for improvement. The traffic flow is usually analyzed from two perspectives mentioned above - macroscopic and microscopic model. [53,57-60].

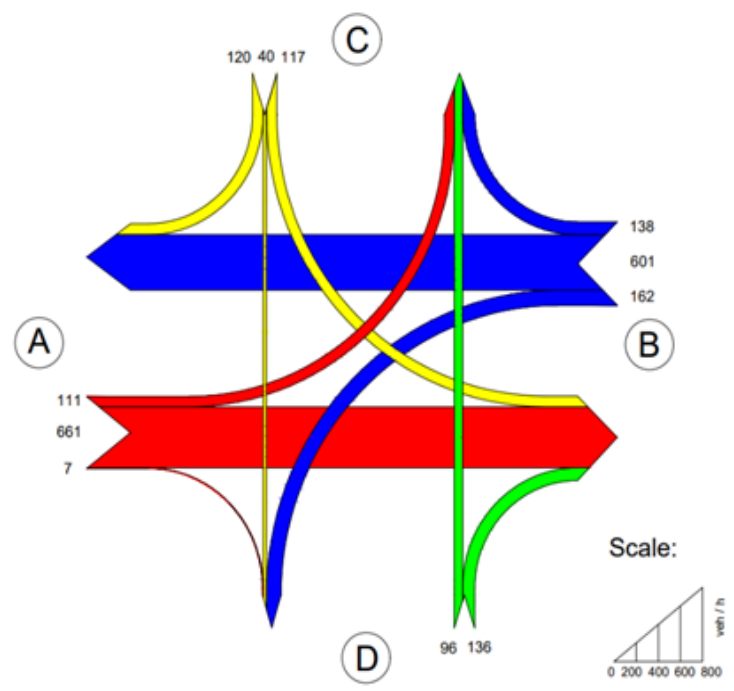

Figure 2: Routing of vehicles throughout the intersection [authors]

\section{RESULTS}

The research conducted aimed at comparing the current state of the intersection by using fixed and actuated control variables. This intersection was modelled on a map background in Aimsun (see fig. 3), where we also inserted an origin/destination matrix of a peak hour (see Table 1), created a signal plan and detectors on entrances at the intersection.

Table 1: Origin/destination matrix [authors]

\begin{tabular}{|c|c|c|c|c|}
\hline & A & B & C & D \\
\hline A & - & 661 & 111 & 7 \\
\hline B & 601 & - & 138 & 162 \\
\hline C & 120 & 117 & - & 40 \\
\hline D & - & 136 & 96 & - \\
\hline
\end{tabular}




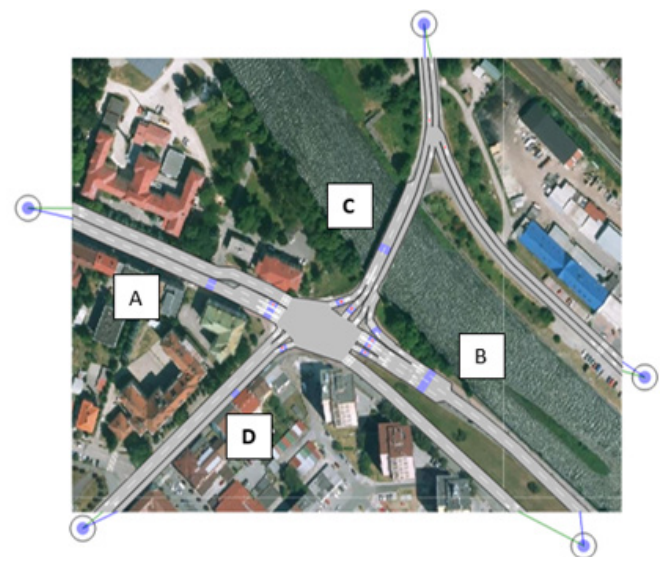

Figure 3 The modelled intersection in Aimsun [authors]

In Aimsun, 10 simulations were performed of the fixed control at the given intersection. An average of these simulations was gathered. Similarly, another 10 simulations were performed for the actuated control, and the average was gathered. Aimsun used detectors on all entrances for actuated control . The following figure 4 shows the simulation in $2 \mathrm{D}$ and $3 \mathrm{D}$ view. All simulations were created during the span of 1 hour (peak hour). We have determined the peak hour $(15: 10$ - 16:10) based on available data.

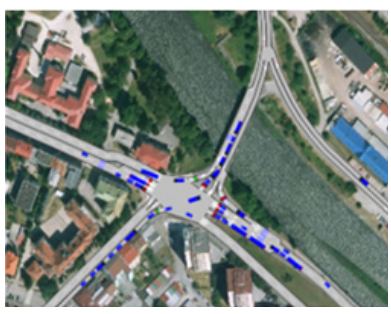

a)

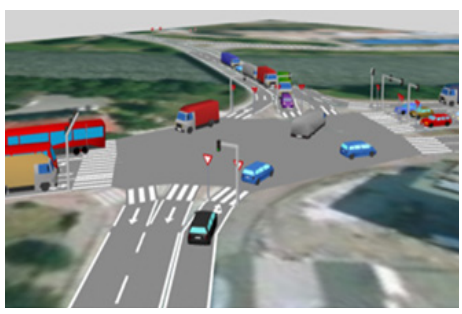

b)
Figure 4: Simulation in Aimsun - (a) $2 D$ view and (b) $3 D$ view [authors]
We were able to compare fixed and actuated control using calculated averages for both control methods. The produced emissions (CO2, NOx and PM), speed, flow and density were compared for cars, trucks and buses. The data gathered demonstrates positive results of actuated control in all comparative values (see Table 2). The green percentage values demonstrate the improvement of the given value for actuated control. Based on the results, it is clear that actuated control is the most efficient and environmentally friendly way to manage intersections. On one hand, it has a positive impact on the basic characteristics of traffic flow to ensure smoother traffic. On another hand, it has a positive impact on emissions production and thus on the environment.

The delay time was also compared for both control methods. In figure 5, you can see the delay times for all road sections in colour and numbers. Some numbers overlap because we had to create several short road sections during modelling. Nevertheless, it is possible to see colour differences in the delay times of both fixed (left) and actuated control (right). In both cases highest delay time was at entrance D. However, it is important to note that the actuated control, was lower by almost $250 \mathrm{~s}$ - a reduction of approximately $85 \%$.

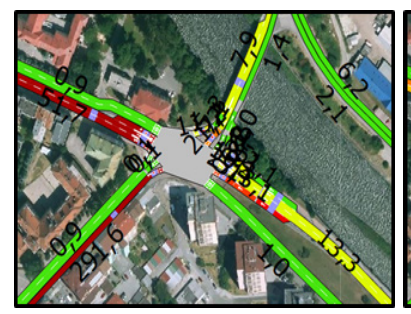

a)

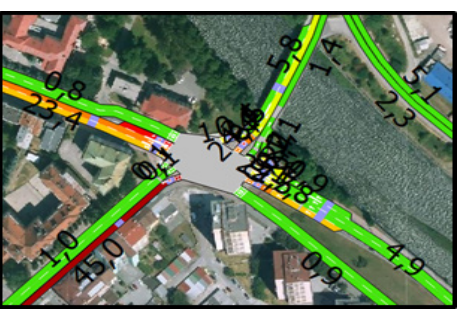

b)
Figure 5: Resulting delay times for fixed (left) and actuated control (right) [authors]

Table 2: Comparison of fixed and actuated control for cars, trucks and buses [authors]

\begin{tabular}{|c|c|c|c|c|c|c|c|}
\hline & & $\begin{array}{c}\text { Flow } \\
(\mathrm{veh} / \mathrm{h})\end{array}$ & $\begin{array}{c}\text { Density } \\
(\mathrm{veh} / \mathrm{km})\end{array}$ & $\begin{array}{c}\text { Speed } \\
(\mathrm{km} / \mathrm{h})\end{array}$ & $\begin{array}{c}\text { CO2 } \\
(\mathrm{g} / \mathrm{km})\end{array}$ & $\begin{array}{c}\text { NOx } \\
(\mathrm{g} / \mathrm{km})\end{array}$ & $\begin{array}{c}\text { PM } \\
(\mathrm{g} / \mathrm{km})\end{array}$ \\
\hline \multirow{4}{*}{ Car } & Fixed & 1553,1 & 14,53 & 20,67 & 505777,1 & 4233,69 & 155,24 \\
\cline { 2 - 8 } & Actuated & 1578,1 & 8,05 & 27,57 & 444168,8 & 3238,16 & 135,45 \\
\cline { 2 - 8 } & Difference & $+1,6 \%$ & $-44,6 \%$ & $+33,4 \%$ & $-12,2 \%$ & $-23,5 \%$ & $-12,7 \%$ \\
\hline \multirow{4}{*}{ Truck } & Fixed & 454,5 & 4,43 & 18,79 & 125231,9 & 1167,64 & 35,69 \\
\cline { 2 - 8 } & Actuated & 471,3 & 2,64 & 25,23 & 111081,3 & 907,12 & 31,03 \\
\cline { 2 - 8 } & Difference & $+3,7 \%$ & $-40,4 \%$ & $+34,3 \%$ & $-11,3 \%$ & $-22,3 \%$ & $-13,1 \%$ \\
\hline \multirow{4}{*}{ Bus } & Fixed & 176,2 & 1,8 & 18,69 & 46648,82 & 453,64 & 12,67 \\
\cline { 2 - 8 } & Actuated & 177,8 & 0,98 & 24,76 & 39005,66 & 327,16 & 10,23 \\
\cline { 2 - 8 } & Difference & $+0,9 \%$ & $-45,6 \%$ & $+32,5 \%$ & $-16,4 \%$ & $-27,9 \%$ & $-19,3 \%$ \\
\hline
\end{tabular}


As mentioned above, the delay time decreased by almost $85 \%$ at entrance $D$ during actuated control at the given intersection. Figure 6 shows the course of the average values of the delay time for all vehicle categories at this entrance in both fixed (yellow) and actuated (blue) control.

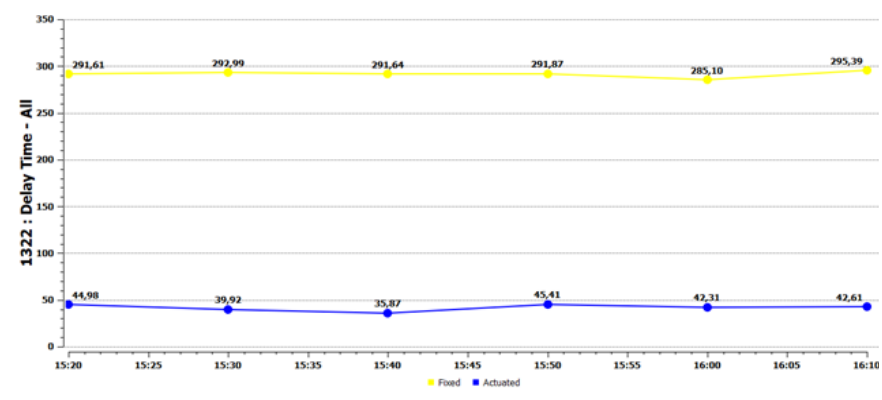

Figure 6:The course of the delay time at the entrance $D$ - fixed and actuated control [authors]

\section{Results at the Entrance $D$}

The following figures 7 - 9 show a comparison of the fixed and actuated control variables for the basic characteristics of the traffic flow at this entrance. It is best to see what changes brought by the actuated control at the intersection. These are average values for all vehicle categories together (car, truck, bus). Values are given for 10-minute intervals (e.g., 15:10 - 15:20, 15:20 - 15:30, etc.). The course of the average speed is shown in Figure 7 . The speed reached higher values during actuated control in comparison to fixed control. Thus, it can be said that the traffic flow was smoother during actuated control when the highest average speed at the entrance D was $12.94 \mathrm{~km} / \mathrm{h}$ and the lowest was $10.71 \mathrm{~km} / \mathrm{h}$. In the case of fixed control, the highest value was $1.42 \mathrm{~km} / \mathrm{h}$ and the lowest was $1.36 \mathrm{~km} / \mathrm{h}$.

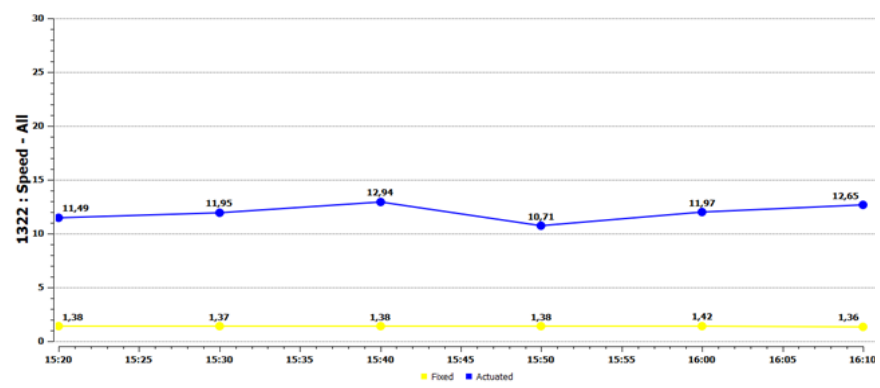

Figure 7: The course of the average speed at the entrance $D$ - fixed and actuated control [authors]

The flow also reached higher values in the case of actuated control (blue colour). At entrance $D$, the maximum flow was $258 \mathrm{veh} / \mathrm{h}$ in the interval 15:40 - 15:50 during the simulation (15:10 - 16:10) with actuated control. With fixed control, the maximum was almost $209 \mathrm{veh} / \mathrm{h}$ (15:50 $-16: 00)$. The course of the average flow is shown below in Figure 8.

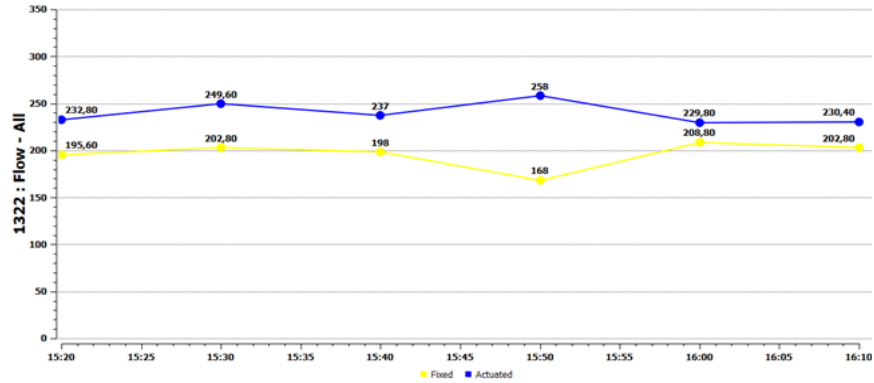

Figure 8: The course of the average flow at the entrance

$D$ - fixed and actuated control [authors]

Figure 9 shows the density course during actuated (blue colour) and fixed control (yellow colour). In this case, the actuated control reached lower density values, which is a favourable result. The total average density value was $29.2 \mathrm{veh} / \mathrm{km}$. With fixed control, the overall average density was $141.37 \mathrm{veh} / \mathrm{km}$. Actuated control achieved approximately $79 \%$ lower average density than fixed control.

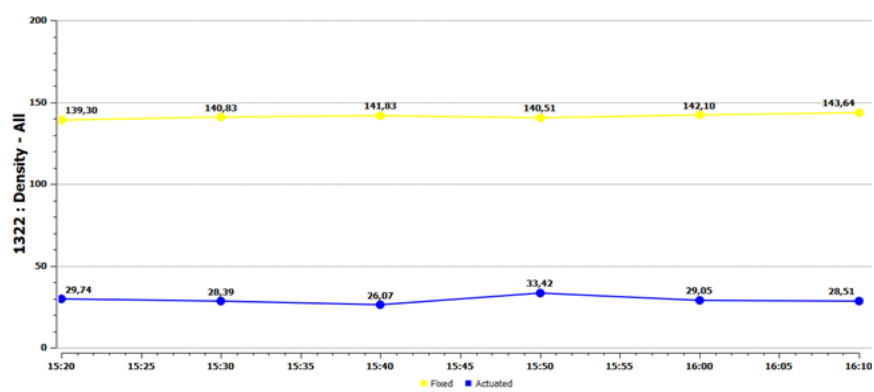

Figure 9: The course of the average density at the entrance $D$ - fixed and actuated control [authors]

Furthermore, we also investigated the impact of actuated control on the environment in terms of produced emissions (CO2, NOx and PM) in comparison to fixed control Fig. 10 shows the course of the average values of $\mathrm{CO} 2$ produced during the simulation for the fixed (yellow colour) and actuated (blue colour) control. The fixed control had a maximum of $146687.04 \mathrm{~g} / \mathrm{km}$ in the interval 15:50 - 16:00. Whereas, the actuated control had a maximum of $62,606.15 \mathrm{~g} / \mathrm{km}$ in the interval 15:40 - 15:50, which represents a decrease of approximately $57 \%$.

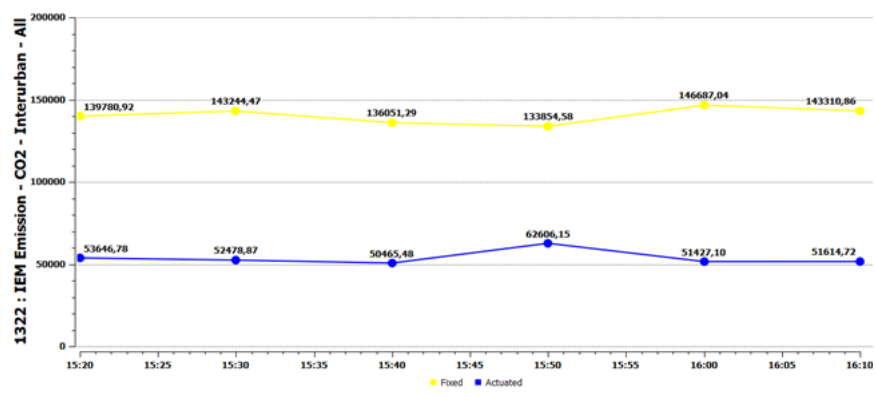

Figure 10: The course of produced CO2 emissions at the entrance $D$ - fixed and actuated control [authors] 
The highest average value of NOx emissions produced was $2289.19 \mathrm{~g} / \mathrm{km}$ in the interval 16:00 - 16:10 during the fixed control (Fig. 11). In the case of actuated control, the maximum was in the interval 15:40 - 15:50 - 629.24 g/ $\mathrm{km}$, which represents a difference of approximately $73 \%$ compared to fixed control.

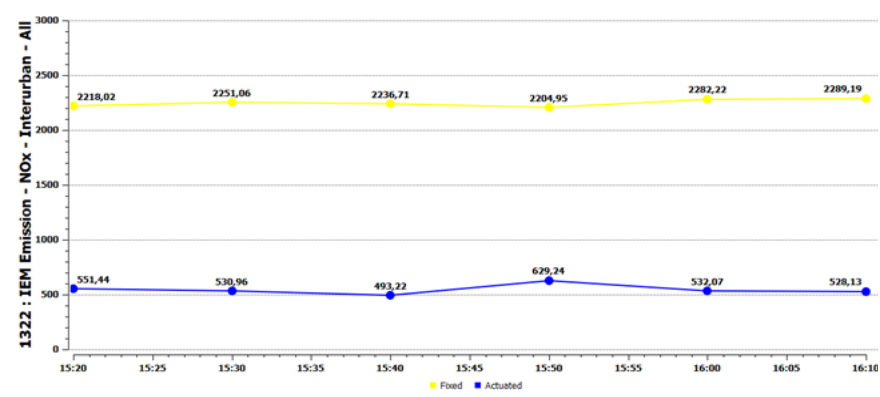

Figure 11: The course of produced NOx emissions at the entrance $D$ - fixed and actuated control [authors]

The course of the average values of produced PM is shown in Figure 12. The maximum value of produced PM under fixed control was $46.23 \mathrm{~g} / \mathrm{km}$ in the interval 15:50 - 16:00. During the actuated control, the maximum of $23.50 \mathrm{~g} / \mathrm{km}$ was reached in the interval 15:40 - 15:50. The difference between these maximum values is approximately $49 \%$.

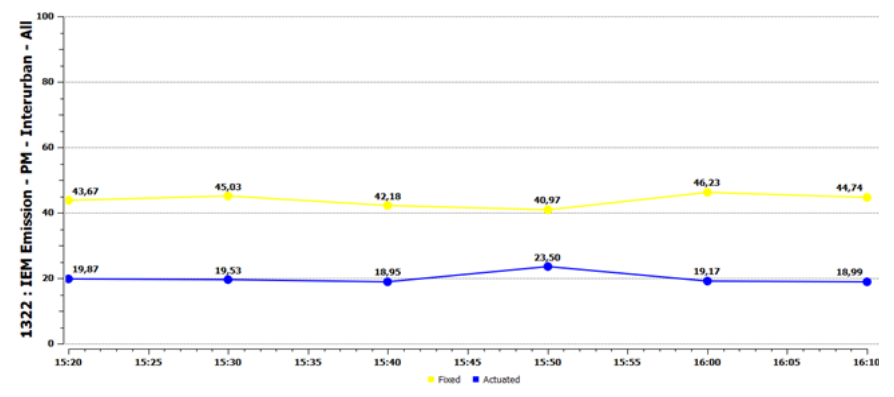

Figure 12: The course of produced PM at the entrance $D$ - fixed and actuated control [authors]

\section{DISCUSSION}

At present, new and innovative solutions are being proposed to ensure efficient and sustainable transport. These solutions are designed based on available traffic data (number of vehicles in congestion, speed, density, flow, etc.). The availability of real-time traffic data is a prerequisite for a suitable solution to improve the current situation. IoT significantly helps to collect that data and propose suitable solutions. Sensors/detectors are the basis of actuated control and used in several transport systems. The traffic data collected at the various intersections are analyzed to ensure intelligent traffic management [61-63]. We have modelled the intersection and performed several simulations in Aimsun. Then, an average was calculated from the outputs. Thus, we obtained the results that are described in the previous chapter. In Chapter 3 - Results, Table 2 shows the resulting comparison of actuated and fixed control for the intersection.
The results show that actuated control had a positive impact on the basic characteristics of the traffic flow (speed, flow and density) as well as on the emissions produced (CO2, NOx and PM). The flow increased on average for all vehicle categories by $2.1 \%$. Vehicle density has decreased by more than $40 \%$ for each category and as a result speed increased by more than $30 \%$ for all vehicle categories. As mentioned previously, actuated control had a positive impact on the environment. $\mathrm{CO} 2$ production of all vehicle categories decreased on average by $13.3 \%$, NOx production by $24.6 \%$ and PM production by $15 \%$ compared to fixed control. Figures $6-12$ shows a comparison of all investigated values at entrance $D$. There were achieved the largest delay times during fixed control. We chose this entrance for the most significant impact of actuated control. A reduction in the delay time of up to $85 \%$ was achieved at this entrance. When comparing the highest average speed values, an increase of more than $800 \%$ was achieved during actuated control. The flow increased slightly and the density decreased on average by more than $79 \%$. The $\mathrm{CO} 2$ emissions were reduced by more than $61 \%$, NOx by more than $75 \%$ and PM by more than $54 \%$.

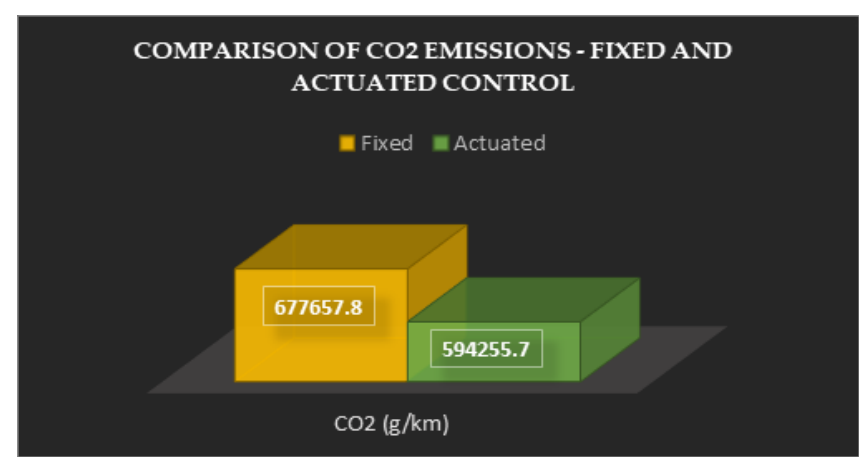

Figure 13 Produced CO2 emissions - fixed and actuated control [authors]

Figure 13 shows a comparison of the $\mathrm{CO} 2$ emissions produced at the intersection for all vehicle categories together. During simulations with actuated control, we achieved a reduction in $\mathrm{CO} 2$ emissions of more than $12 \%$.

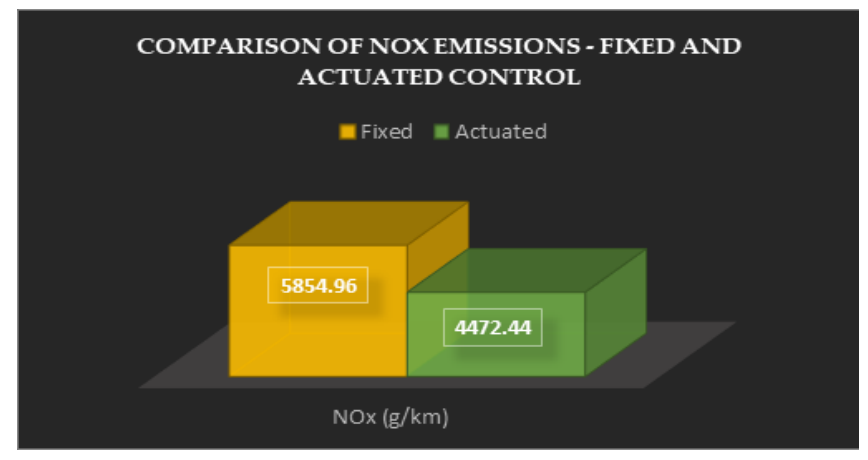

Figure 14: Produced NOx emissions - fixed and actuated control [authors] 
A comparison of the NOx emissions produced at the intersection for all vehicle categories together can be seen in Figure 14. Using actuated control, we achieved a reduction of more than $23 \%$ in the NOx emissions produced.

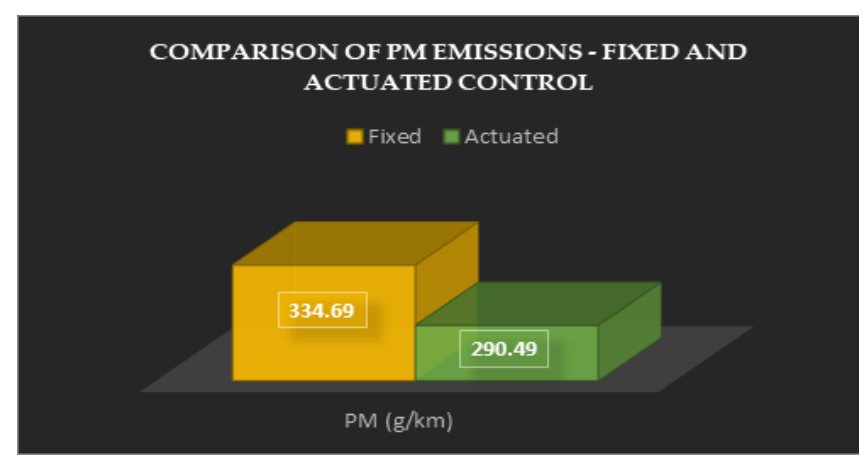

Figure 15: Produced PM emissions - fixed and actuated control [authors]

Figure 15 shows a comparison of the PM produced at the intersection for all vehicle categories. During simulations with actuated control, a reduction of more than $13 \%$ of PM produced was achieved. The achieved results show that the implementation of actuated control at signal-controlled intersections has a positive impact on the basic characteristics of the traffic flow as well as the environment. Environmental pollution and ways to reduce this negative phenomenon are topical problems. Transport has a great negative impact on the environment. Therefore, it is vital to look for solutions to reduce this impact. In our research, we compared fixed and actuated control not only in terms of environmental impact but also in terms of impact on traffic flow. In both cases, we have achieved positive results and it is possible to conclude that the implementation of this control at all signal-controlled intersections can be a great benefit to road transport. There are still many intersections in Slovakia that are not managed based on the current traffic situation. Several studies describe actuated control at intersections from different views and compare them with fixed control. The study [63] describes the results of reduced delays and travel times by $36 \%$ and $17 \%$, simulteanously. According to the study [65], the authors describes a $5 \%$ reduction of delays and stop times. Also noted is a reduction of vehicular delays by $5-15 \%$. In the study [66], the authors developed CAPACITEL (a new mesomodel). They obtained a reduction in vehicle and bus delays in comparison to Akcelik (29\% and 22\%) and Webster (39\% and 53\%). However, these studies do not compare actuated and fixed control in terms of environmental impact. Several studies deal with emissions production at signal-controlled intersections. According to the study [67], traffic lights cause an increase in CO2 emissions because of traffic jams created during the red lights. A further increase in $\mathrm{CO} 2$ emissions is noted when the light turns green and vehicles begin to accelerate.

In addition to actuated control, it is possible to dynamically manage traffic in the form of the DSL systems (see Introduction). These systems can help reduce congestion and ensure a smoother traffic flow. According to the study [68], the investigated DSLs on motorways in Flanders (Belgium) helped to reduce injury crashes (18\% reduction). Transport is one of the biggest polluters of the environment. Therefore, it is necessary to not only influence the production of pollutants through actuated control but also by supporting vehicles with an electric propulsion or other ecological energy sources (eg hydrogen, biofuel). Also, it is important to support smart mobility solutions. We want to continue our research by taking into account the impact of speed on fixed and actuated control - how increased or decreased vehicle speed will affect the flow of traffic and the impact on the environment.

\section{CONCLUSIONS}

Real traffic at intersections is a sophisticated phenomenon with several traffic participants. In fixed control methods, the systems operate on several predetermined signal plans. Traffic changes are not considered in such controlled situations. Therefore, the performance of this control under variable traffic conditions is inefficient. Actuated control systems are used to overcome this problem. Changes in green signal length and phase order can be dynamically updated. This provides the flexibility to increase the capacity and smoothness of the traffic flow at intersections as well as minimize time spent at traffic stops by all traffic participants. At present, great emphasis is placed on the impact on the environment. Thanks to the ensured smoothness of traffic, it is possible to achieve a reduction in emissions. Our simulation results also brought us positive results in terms of emissions produced, where we compared fixed and actuated control at the intersection. Based on the results achieved, actuated control must be gradually implemented at all signal-controlled intersections, thus reducing emissions and increasing traffic flow.

\section{Acknowledgments}

We would like to thank Siemens Mobility for provided traffic data and signal plans of solved signal-controlled intersection

\section{Funding}

This research was funded by the grant project of the University of Zilina - Basic research into the causes of transport system failure (grant number 12294).

\section{REFERENCES}

1. Dameri, R.P., Benevolo, C. (2017). ICT Intensity in Smart Mobility Initiatives. Smart City Implementation. Springer, Switzerland, p. 85-108. DOI: https:// doi.org/10.1007/978-3-319-45766-6_5. 
2. Sun, X., Lin, K., Jiao, P., Lu, H. (2020). The Dynamical Decision Model of Intersection. Congestion Based on Risk Identification. Sustainability 2020 , vol. 12, no. 15, DOI: https://doi.org/10.3390/su12155923.

3. Vlahogianni, E.I., Karlaftis, M.G., Kepaptsoglou, K. (2011). Nonlinear autoregressive conditional duration models for traffic congestion estimation. Journal of Probability and Statistics, vol. 2011, p. 1-13. DOI: https://doi.org/10.1155/2011/798953.

4. Wang, Y., Rong, J., Zhou, C., Gao, Y. (2020). Dynamic Estimation of Saturation Flow Rate at Information-Rich Signalized Intersections. Information, vol. 11, no. 4, DOI: https://doi.org/10.3390/info11040178.

5. Albalate, D., Fageda, X. (2019). Congestion, road safety, and the effectiveness of public policies in urban areas. Sustainability, vol. 11, no. 18, DOI: https:// doi.org/10.3390/su11185092.

6. Li, J., Dridi, M., El-Moudni, A. (2016). A Cooperative Traffic Control of Vehicle-Intersection (CTCVI) for the Reduction of Traffic Delays and Fuel Consumption. Sensors, vol. 16, no. 12, DOI: https://doi. org/10.3390/s16122175.

7. Xia, X., Ma, X., Wang, J. (2019). Control Method for Signalized Intersection with Integrated Waiting Area. Applied Sciences, vol. 9, no. 5, DOI: https:// doi.org/10.3390/app9050968.

8. Wu, J., Liu, P., Qin, X., Zhou, H., Yang, Z. (2019). Developing an actuated signal control strategy to improve the operations of contraflow left-turn lane design at signalized intersections. Transportation research part C: emerging technologies, vol. 104, p. 5365. DOI: https://doi.org/10.1016/j.trc.2019.04.028.

9. Mayeres, I., Ochelen, S., Proost, S. (1996). The marginal external costs of urban transport, Transportation Research Part D: Transport and Environment, vol. 1, no. 2, p. 111-130, DOI: https://doi.org/10.1016/ S1361-9209(96)00006-5.

10. Black, J. (2018). Urban transport planning: Theory and practice. Routledge. ISBN: 135106858X.

11. Abduljabbar, R., Dia, H., Liyanage, S., Bagloee, S.A. (2019). Applications of artificial intelligence in transport: An overview. Sustainability, vol. 11, no. 1, DOI: https://doi.org/10.3390/su11010189.

12. Liyanage, S., Dia, H. (2020). An Agent-Based Simulation Approach for Evaluating the Performance of On-Demand Bus Services. Sustainability, vol. 12, no. 10, DOI: https://doi.org/10.3390/su12104117.

13. Moslem, S., Duleba, S. (2019). Sustainable Urban Transport Development by Applying a Fuzzy-AHP Model: A Case Study from Mersin, Turkey. Urban Science, vol. 3, no. 2, DOI: https://doi.org/10.3390/ urbansci3020055.
14. Konečný, V., Gnap, J., Settey, T., Petro, F., Skrúcaný, T., Figlus, T. (2020). Environmental Sustainability of the Vehicle Fleet Change in Public City Transport of Selected City in Central Europe. Energies, vol. 13, no. 15, DOI: https://doi.org/10.3390/en13153869.

15. Glotz-Richter, M., Koch, H. (2016). Electrification of Public Transport in Cities (Horizon 2020 ELIPTIC Project). Transportation Research Procedia, vol. 14, p. 2614-2619, DOI: https://doi.org/10.1016/j.trpro.2016.05.416.

16. Guno, C.S., Collera, A.A., Agaton, C.B. (2021). Barriers and Drivers of Transition to Sustainable Public Transport in the Philippines. World Electric Vehicle Journal, vol. 12, no. 1, DOI: https://doi.org/10.3390/ wevj12010046.

17. Barbarossa, L. (2020). The Post Pandemic City: Challenges and Opportunities for a Non-Motorized Urban Environment An Overview of Italian Cases. Sustainability, vol. 12, no. 17 , DOI: https://doi. org/10.3390/su12177172.

18. Soin, A., Chahande, M. (2017). Moving vehicle detection using deep neural network. International Conference on Emerging Trends in Computing and Communication Technologies (ICETCCT) 2017, p. 1-5. DOI: 10.1109/ICETCCT.2017.8280336.

19. Li, Y., Tian, B., Li, B., Xiong, G., Zhu, F., Wang, K. (2013). Vehicle detection with a part-based model for complex traffic conditions. International Conference on Vehicular Electronics and Safety, 2013, p. 110-113, DOI: 10.1109/ICVES.2013.6619613.

20. Poliak, M., Poliakova, A., Mrnikova, M., Šimurková, P., Jaśkiewicz, M., Jurecki, R. (2017). The competitiveness of public transport. Journal of Competitiveness, vol. 9 no. 3, p. 81-97, DOI: https://doi. org/10.7441/joc.2017.03.06.

21. Nie, C., Wei, H., Shi, J., Zhang, M. (2021). Optimizing actuated traffic signal control using license plate recognition data: Methods for modeling and algorithm development. Transportation Research Interdisciplinary Perspectives, vol. 9, DOI: https://doi. org/10.1016/j.trip.2021.100319.

22. Mangiaracina, R., Perego, A., Salvadori, G., Tumino, A. (2016). A comprehensive view of intelligent transport systems for urban smart mobility. International Journal of Logistics Research and Applications, vol. 20, no. 1, p. 1-14. DOI: https://doi.org/10.1080/1367 5567.2016.1241220.

23. Papageorgiou, M., Ben-Akiva, M., Bottom, J., Bovy, P.H.L., Hoogendoorn, S.P., Hounsell, N.B., McDonald, M. (2007). ITS and Traffic Management. Barnhart, C., Laporte, G., Handbooks in Operations Research and Management Science. Elsevier, vol. 14, p. 715-774. DOI: https://doi.org/10.1016/S09270507(06)14011-6. 
24. Moghimi, B., Safikhani, A., Kamga, C., Hao, W. (2018). Cycle-length prediction in actuated traffic-signal control using ARIMA model. Journal of Computing in Civil Engineering, vol. 32, no. 2, DOI: 10.1061/(ASCE)CP.1943-5487.0000730.

25. Shiri, M. S., Maleki, H. R. (2017). Maximum green time settings for traffic-actuated signal control at isolated intersections using fuzzy logic. International Journal of Fuzzy Systems, vol. 19, no. 1, p. 247-256. DOI: $10.1007 / \mathrm{s} 40815-016-0143-7$.

26. Wang, X. B., Yin, K., Liu, H. (2018). Vehicle actuated signal performance under general traffic at an isolated intersection. Transportation research part C: emerging technologies, vol. 95, p. 582-598, DOI: https://doi.org/10.1016/j.trc.2018.08.002.

27. Nie, C., Wei, H., Shi, J., Zhang, M. (2021). Optimizing actuated traffic signal control using license plate recognition data: Methods for modeling and algorithm development. Transportation Research Interdisciplinary Perspectives, vol. 9, DOI: https://doi. org/10.1016/j.trip.2021.100319.

28. Toledo, T., Balasha, T., Keblawi, M. (2020). Optimization of Actuated Traffic Signal Plans Using a Mesoscopic Traffic Simulation. Journal of Transportation Engineering, Part A: Systems, vol. 146, no. 6, DOI: $10.1061 /$ JTEPBS.0000363.

29. Al Islam, S. B., Hajbabaie, A., Aziz, H. A. (2020). A real-time network-level traffic signal control methodology with partial connected vehicle information. Transportation Research Part C: Emerging Technologies, vol. 121, DOI: https://doi.org/10.1016/j. trc.2020.102830.

30. Yao, Z., Jiang, Y., Zhao, B., Luo, X., Peng, B. (2020). A dynamic optimization method for adaptive signal control in a connected vehicle environment. Journal of Intelligent Transportation Systems, vol. 24, no. 2, p. 184-200, DOI: https://doi.org/10.1080/15472450. 2019.1643723.

31. Astarita, V., Giofré, V. P., Festa, D. C., Guido, G., Vitale, A. (2020). Floating car data adaptive traffic signals: A description of the first real-time experiment with "connected" vehicles. Electronics, vol. 9, no. 1, DOI: https://doi.org/10.3390/electronics9010114.

32. Wang, Y., Yang, X., Liang, H., Liu, Y. (2018). A review of the self-adaptive traffic signal control system based on future traffic environment. Journal of Advanced Transportation, vol. 2018, DOI: https://doi. org/10.1155/2018/1096123.

33. Zhu, L., Yu, F. R., Wang, Y., Ning, B., Tang, T. (2018). Big data analytics in intelligent transportation systems: A survey. IEEE Transactions on Intelligent Transportation Systems, vol. 20, no. 1, p. 383-398, DOI: 10.1109/TITS.2018.2815678.
34. Liu, Y., Liu, L., Chen, W. P. (2017). Intelligent traffic light control using distributed multi-agent $Q$ learning. International Conference on Intelligent Transportation Systems (ITSC), 2017, p. 1-8, DOI: 10.1109/ ITSC.2017.8317730.

35. El-Tantawy, S., Abdulhai, B., Abdelgawad, H. (2014). Design of reinforcement learning parameters for seamless application of adaptive traffic signal control. Journal of Intelligent Transportation Systems, vol. 18, no. 3, p. 227-245, DOI: https://doi.org/10.10 80/15472450.2013.810991.

36. Prabuchandran, K. J., AN, H. K., Bhatnagar, S. (2014). Multi-agent reinforcement learning for traffic signal control. International IEEE Conference on Intelligent Transportation Systems (ITSC), 2014, p. 2529-2534, DOI: 10.1109/ITSC.2014.6958095.

37. Wei, H., Zheng, G., Yao, H., Li, Z. (2018). Intellilight: A reinforcement learning approach for intelligent traffic light control. International Conference on Knowledge Discovery \& Data Mining, 2018, p. 2496-2505, DOI: https://doi.org/10.1145/3219819.3220096.

38. Li, L., Lv, Y., Wang, F. Y. (2016). Traffic signal timing via deep reinforcement learning. IEEE/CAA Journal of Automatica Sinica, vol. 3, no. 3, p. 247-254, DOI: 10.1109/JAS.2016.7508798.

39. Shabestary, S. M. A., Abdulhai, B. (2018, November). Deep learning vs. discrete reinforcement learning for adaptive traffic signal control. International Conference on Intelligent Transportation Systems (ITSC), 2018, p. 286-293, DOI: 10.1109/ ITSC.2018.8569549.

40. Zeng, J., Hu, J., Zhang, Y. (2018, June). Adaptive traffic signal control with deep recurrent Q-learning. IEEE Intelligent Vehicles Symposium (IV), 2018, p. 1215-1220, DOI: 10.1109/IVS.2018.8500414.

41. Liang, X., Du, X., Wang, G., Han, Z. (2018). Deep reinforcement learning for traffic light control in vehicular networks. IEEE Transactions on Vehicular Technology, vol. 68, no. 2, p. 1243-1253, DOI: 10.1109/ TVT.2018.2890726.

42. Porru, S., Misso, F. E., Pani, F. E., Repetto, C. (2020). Smart mobility and public transport: Opportunities and challenges in rural and urban areas. Journal of Traffic and Transportation Engineering (English Edition), vol. 7, no. 1, p. 88-97, DOI: https:// doi.org/10.1016/j.jtte.2019.10.002.

43. Anastasiadou, K., Vougias, S. (2019). "Smart" or "sustainably smart" urban road networks? The most important commercial street in Thessaloniki as a case study. Transport Policy, vol. 82, p. 18-25, DOI: https://doi.org/10.1016/j.tranpol.2019.07.009.

44. Islam, M. T., Hadiuzzaman, M., Fang, J., Qiu, T. Z., El-Basyouny, K. (2013). Assessing mobility and safety impacts of a variable speed limit control strategy. Transportation research record, vol. 2364, no. 1, p. 1-11, DOI: https://doi.org/10.3141/2364-01. 
45. Habtemichael, F. G., de Picado Santos, L. (2013). Safety and Operational Benefits of Variable Speed Limits under Different Traffic Conditions and Driver Compliance Levels. Transportation Research Record, vol. 2386, no. 1, p. 7-15, DOI: https://doi. org/10.3141/2386-02.

46. Lu, X.-Y., Shladover, S. E. (2014). Review of Variable Speed Limits and Advisories: Theory, Algorithms, and Practice. Transportation Research Record, vol. 2423, no. 1, p. 15-23, DOI: https://doi. org/10.3141/2423-03.

47. Harms, I. M. Brookhuis, K. A. (2016). Dynamic traffic management on a familiar road: Failing to detect changes in variable speed limits. Transportation Research Part F: Traffic Psychology and Behaviour, vol. 38, p. 37-46, DOI: https://doi.org/10.1016/j. trf.2016.01.005.

48. Nasir, M. K., Md Noor, R., Kalam, M. A., Masum, B. M. (2014). Reduction of fuel consumption and exhaust pollutant using intelligent transport systems. The Scientific World Journal, vol. 2014, DOI: https:// doi.org/10.1155/2014/836375.

49. Faisal, A., Yigitcanlar, T., Kamruzzaman, M., Currie, G. (2019). Understanding autonomous vehicles: a systematic literature review on capability, impact, planning and policy. Journal of Transport and Land Use, vol. 12, no. 1, DOI: https://doi.org/10.5198/ jtlu.2019.1405.

50. Dimitrakopoulos, G., Uden, L., Varlamis, I. (2020). Intelligent transport systems and smart mobility. The Future of Intelligent Transport Systems, Elsevier, 2020, p. 199-205, DOI: https://doi.org/10.1016/ B978-0-12-818281-9.00018-8.

51. Poliak, M., Svabova, L., Konecny, V., Zhuravleva, N. A., Culik, K. (2021). New paradigms of quantification of economic efficiency in the transport sector . Oeconomia Copernicana, 12(1), 193-212. https:// doi.org/10.24136/oc.2021.008.

52. https://sk.mapy.cz/

53. Casas J., Ferrer J.L., Garcia D., Perarnau J., Torday A. (2010). Traffic Simulation with Aimsun. In: Barceló J. (eds) Fundamentals of Traffic Simulation. International Series in Operations Research \& Management Science, vol 145. Springer, New York, NY. https://doi. org/10.1007/978-1-4419-6142-6_5
54. TSS - TRANSPORT SIMULATION SYSTEMS. Microsimulator and Mesosimulator Aimsun 8.1 User's Manual, accessed on 2021-06-06.

55. Panis, L. I., Broekx, S., Liu, R. (2006). Modelling instantaneous traffic emission and the influence of traffic speed limits. Science of the total environment, vol. 371, no. 1-3, p. 270-285. DOI: https://doi. org/10.1016/j.scitotenv.2006.08.017.

56. Barceló, J., Casas, J. (2005). Dynamic network simulation with AIMSUN. Simulation approaches in transportation analysis, vol. 31, p. 57-98, DOI: https://doi.org/10.1007/0-387-24109-4_3.

57. Leitner, B. (2014). Možnosti testovania parametrov dopravného prúdu pri strate funkčnosti vybraného prvku cestnej siete. Perners Contacts, vol. 9, no. 1, p. 120-131.

58. Banks, J., Carson, J., Nelson, B., Nicol, D. (2001). Discrete-Event System Simulation, Prentice Hall. P. 3. ISBN 978-0-13-088702-3.

59. Ifenthaler, D. (2012). Computer Simulation Model. Encyclopedia of the Sciences of Learning, DOI: https://doi.org/10.1007/978-1-4419-1428-6_500.

60. Cruzado, I., Donnell, E. T. (2009). Evaluating Effectiveness of Dynamic Speed Display Signs in Transition Zones of Two-Lane, Rural Highways in Pennsylvania. Transportation Research Record, vol. 2122, no. 1, p. 1-8, DOI: https://doi.org/10.3141/2122-01.

61. Sinhmar, P. (2012). Intelligent traffic light and density control using IR sensors and microcontroller. International journal of advanced technology \& engineering research (IJATER), vol. 2, no. 2, p. 30-35.

62. Geetha, E., Viswanadha, V., Kavitha, G. (2014). Design of intelligent auto traffic signal controller with emergency override. International journal of engineering science and innovative technology (IJESIT), vol. 3, no. 4, p. 670-675.

63. Jadhav, A., Madhuri, B., Ketan, T. (2014). Intelligent traffic light control system (ITLCS). 4th IRF international conference.

64. Park, B., Schneeberger, J. D. (2003). Evaluation of traffic signal timing optimization methods using a stochastic and microscopic simulation program. Virginia Transportation Research Council. 
65. Stevanovic, A., Martin, P. T., Stevanovic, J. (2007). VisSim-Based Genetic Algorithm Optimization of Signal Timings. Transportation Research Record, vol. 2035, no. 1, p. 59-68. DOI: https://doi. org/10.3141/2035-07.

66. Wolput, B., Christofa, E., Carbonez, A., Skabardonis, A., Tampère, C. (2015). Optimal traffic signal settings with transit signal priority. Proceedings of the 94th Annual Meeting of the Transportation Research Board, vol. 1115, p. 119.
67. Lakouari, N., Oubram, O., Bassam, A., Hernandez, S. E. P., Marzoug, R., Ez-Zahraouy, H. (2020). Modeling and simulation of $\mathrm{CO} 2$ emissions in roundabout intersection. Journal of Computational Science, vol. 40, DOI: https://doi.org/10.1016/j.jocs.2019.101072.

68. De Pauw, E., Daniels, S., Franckx, L., Mayeres, I. (2018). Safety effects of dynamic speed limits on motorways. Accident Analysis \& Prevention, vol. 114, p. 83-89. DOI: https://doi.org/10.1016/j. aap.2017.06.013. 